\title{
RECENT CHANGES IN THE ALPINE GRASSLANDS OF THE WEST COAST
}

Forest Research Institute, Christchurch

Abstruct

\begin{abstract}
A full range of both tall and short snowgrass communities are present within the alpine grassland region of the West Coast; Many of the intertussock, fleshy herbs were removed with the initial grazing by wild animals, while the stature of many of the tall tussock communities was reduced with continual heavy grazing. Once major animal control operations were undertaken, a dramatic recovery in stature was recorded on the most favourable sites. This initial response could be very rapid as the tussocks required only a reduction in grazing pressure to attain their full stature.
\end{abstract}

\section{INTRODUCTION}

WHEN considering grasslands on the West Coast, the main preoccupation is with the developed grazing pasures along the major rivers. However, the largest area of grassland on the West Coast is contained within the indigenous tussock grasslands above timberline of the high altitude ridges and valleys bordering the main divide. No pastoral use is made of these grasslands although a few attempts were made to graze sheep during the 1890s.

Though no direct econmic return was produced by these grasslands until the late $1960 \mathrm{~s}$, they were subjected to the same intensive abuse by introduced wild animals as were their protection forest counterparts at lower altitudes. Large-scale animal control operations have been conducted in most catchments of the West Coast from the Buller in the north to the Haast-Arawata in the south.

The earliest control methods involved the use of ground hunters while later operations, especially in the late 1960s, involved the harvesting of venison for export by helicopters, and presentday operations involve the live capture of animals for increasing domestic breeding stock. 


\section{COMMUNITIES AND DISTRIBUTION}

A full range of tall and short tussock communities, as determined by their physiognomic dominant Chionochloa species, are present and many have been described (Wraight, 1960; Evans, 1970; Wardle, 1977).

The tall tussock forms dominated by Chionochloa pallens and C. flavescens are the most abundant above timberline on sites with a snow-free growing season longer than 5 months. The short tussock grasslands dominated by Chionochloa crassiuscula and $C$. oreophila become abudant at the higher altitudes and in the hollows where the snow-free period is reduced to 3 or 4 months. Chionochloa species with a more restricted distribution are àlso found. In the north on the drier sites, associations with C. australis become important, and $C$. rubra becomes dominant on poorly drained sites near timberline.

\section{CHANGES IN STRUCTURE AND COMPOSITION}

During the inntial period of heavy grazing pressure by wild animals, mainly deer and secondly chamois, many of the tall tussock communities were reduced in stature to short tussock communities dominated by $\mathbf{C}$. crassiuscula and $\mathbf{C}$. oreophila. Continual grazing * of these communities saw the removal of many of the intertussock fleshy herbs, which contained higher nutrient concentrations than the surrounding tussocks. This high nutrient concentration probably indicates a higher palatability, hence accentuating their susceptibility 'to removal as these species contribute only a very small proportion to the total phytomass. Once the grasslands had been reduced from a dense sward with a large litter component to an open sward with only a small quantity of intertussock litter, many of the woody herbs became dominant members of the intertussock communities. With the removal of a large proportion of the litter component, many of the soils were readily des'troyed by trampling and water movement, particularly within the animal tracks.

Once the major animal control operations began, dramatic changes resulted in the vegetation particularly in the tall tussock communities on the most favourable sites. In. these areas the tussocks had acquired an inverted cone shape during grazing but they quickly assumed their normal lax convex shape once the grazing pressure was reduced. This change was solely due to the increased leaf length and to the increased number of tillers present within the tussock crown. In many of the induced short tussock 
communities, the tall Chionochloa species reappeared once grazing was reduced because of the rapid regrowth and initiation of new tillers on the old plants which had been reduced to only two or three tillers. These initial responses were very rapid, requiring as little as 3 to 4 years as the plants were still present and only needed to develop their full stature.

In contrast, changes in species composition have occurred very slowly and even after measuring changes on some plots for 20 years the number of new individuals invading the sward is minimal. A trend indicating an increase in the fleshy mesophytic herbs with a reduction in the woody herbs is beginning to appear, but again only on the more favourable sites.

Unfortunately, the dramatic improvements in stature and the minor changes in composition are limited to approximately 10 to $20 \%$ of the plots established within the alpine grasslands and these are usually located on nutrient-rich sites associated with some protection and a warm aspect. At the majority of sites $(60 \%)$ no change has occurred, and the remaining 20 to $30 \%$ have shown only minor improvements.

\section{REFERENCES}

Evans, G. R., 1970. The alpine grasslands of the Taramakau River catchment. NZFS Prot. For. Rep. No. 61 (unpubl.).

Wardle, P., 1977. N.Z. $/ l$ Bot.. 15: 323-98

Wraight, M. J., 1960. N.Z. Jl Sci., 3: 306-32. 